\title{
Corpus
}

Archivos virtuales de la alteridad americana

Vol. 8, No $2 \mid 2018$

Julio / Diciembre 2018

\section{Despaisamiento, inmundo, comunidades emergentes}

Jens Andermann

\section{CpenEdition}

Journals

\section{Electronic version}

URL: http://journals.openedition.org/corpusarchivos/2701

DOI: 10.4000/corpusarchivos. 2701

ISSN: $1853-8037$

\section{Publisher}

Diego Escolar

\section{Electronic reference}

Jens Andermann, «Despaisamiento, inmundo, comunidades emergentes », Corpus [En línea], Vol. 8, No 2 | 2018, Publicado el 25 diciembre 2018, consultado el 19 abril 2019. URL : http:// journals.openedition.org/corpusarchivos/2701; DOI : 10.4000/corpusarchivos.2701

This text was automatically generated on 19 April 2019

Licencia Creative Commons: Atribución-NoComercial 2.5 Argentina (CC BY-NC 2.5 AR) 


\title{
Despaisamiento, inmundo, comunidades emergentes
}

\author{
Jens Andermann
}

1 En una secuencia del documental Manufactured Landscapes (2006) de Jennifer Baichwal sobre el trabajo del fotógrafo canadiense Edward Burtinsky (2006), este último y su equipo aparecen preparando una de sus características tomas panorámicas desde una plataforma elevada delante de una inmensa cordillera artificial de escoria carbónica que se extiende hasta el horizonte. Mientras Burtinsky prepara sus lentes, un asistente discute con los supervisores chinos quienes, en el último momento, expresan dudas sobre el impacto que las fotografías podrían tener sobre la imagen del país, pero que acaban cediendo una vez que se les haya mostrado el último libro cuidadosamente editado del artista con imágenes tomadas, se apresta a explicar el asistente, en sitios mineros estadounidenses y canadienses: "he'll make it look beautiful" - él lo hará aparecer bello, los tranquiliza. Efectivamente, esa es la provocación que subtiende a la obra de Burtinsky, estética y políticamente discutible pero indudablemente eficaz: enfocar las tierras violentadas que enfrenta su cámara de la única manera en que lo sabe hacer el dispositivo fotográfico, como si aún fueran un paisaje. Paisaje que, por otra parte, apela antes a la tradición de lo sublime de lo bello, esto es, a la noción de una inmensidad que desborda nuestras facultades sensoriales pero que, en tanto imagen, no obstante atestigua el triunfo del espíritu al haber plasmado ese desconcierto en idea, en representación (Kant). Esa tensión entre las dos aceptaciones de lo sublime que ya era central para la modernidad, se acentúa aún más en el trabajo de Burtinsky donde aquello que devuelve la imagen contradice desde el inicio la exterioridad del mundo-objeto respecto de su observador, relación en la que se había fundado el propio género paisajista. Aquí, lo que desborda nuestra percepción -lo que supera nuestra capacidad de juicio, en lenguaje kantiano- es manifiestamente el resultado de intervenciones humanas en las materialidades que están a la vista y no, como en el sublime natural, de su muda indiferencia ante nuestros quehaceres. O mejor dicho, eso que surge delante de las lentes de Burtinsky son materialidades indiferentes e irritables a la vez, son la "Gaia quisquillosa" cuya irrupción ha constatado Isabelle Stengers (2015, pp. 43-51) y que pone en suspenso no solo al sujetoobservador del paisaje occidental sino a la supervivencia misma de lo humano como 
especie y aún de lo viviente en su configuración y ontología terrestre. La plataforma desde donde Burtinsky toma sus fotos -porque siempre exigen una plataforma- no es sino eso: el mirador del fin del mundo.

2 Al terminar recientemente una investigación que ya parecía eterna sobre el agotamiento de la forma paisaje y la emergencia de nuevas estéticas "terráneas" (para usar el neologismo de Bruno Latour) en las artes contemporáneas (Andermann 2018), me di con la sorpresa de que en este mirador, al que había ascendido trabajosamente a través de los archivos literarios, plásticos y fílmicos de la modernidad latinoamericana, ya se había dado cita una multitud de visitantes quienes, para permanecer en la imagen, habían viajado allí en el funicular de la gran teoría. Me refiero, por supuesto, a la enorme producción teórica en los últimos años en torno a los 'fines del mundo', para citar el título en inglés del libro reciente de Déborah Danowski y Eduardo Viveiros de Castro (2017), donde la posibilidad empírica de extinción de lo viviente tal y como resulta sugerida por datos estratigráficos y oceanográficos, ha desencadenado una ola de especulaciones ontológicas y cosmológicas. Está en juego, en palabras de Elizabeth Povinelli (2016), nada menos que la relación entre bios y geos en condiciones de cambio climático antropogénico. En ese contexto, "frente a Gaia" (como tituló Latour sus clases magistrales en la Universidad de Edimburgo), me pregunto cuán relevantes son aún los vericuetos de una forma estética anacrónica como la del paisaje en América Latina, vistos desde la inconmensurabilidad del nuevo "híperobjeto" cuya extensión en tiempo y espacio habría hecho estallar hoy las fundaciones mismas de cualquier saber disciplinario (Morton 2013). ¿Habrá, al fin y al cabo, alguna virtud en haber llegado al mirador del fin del mundo, a través de la producción estética de los márgenes coloniales de Occidente? ¿O estaríamos meramente repitiendo el viejo ritual de incorporación regionalizante, y por tanto derivativa y tardía, de paradigmas acuñados en otra parte?

3 Ahora bien, uno de los efectos desconcertantes de ese giro terráneo en el pensamiento actual remite precisamente a problemas de escala, del dónde y cuándo de las manifestaciones de aquello que aún no sabemos nombrar (¿antropoceno o antropozóico? ¿o capitaloceno, chthuluceno, necroceno?). "En la época del calentamiento global", dice Morton, la relación entre fondo y figura, primer y segundo plano, centros y periferias, que alguna vez llamamos mundo se escurrió inexorablemente (Morton 2013, p. 99). El fin del mundo y el fin del paisaje coinciden porque la experiencia de, literalmente, humillación a la que nos enfrentan los nuevos ensamblajes de materialidades/vitalidades en trance que nos echan en cara nuestros esfuerzos por estabilizarlas en imagen y en repositorio de recursos, nos ha privado de cualquier horizonte, de 'mundo'. No otra es la experiencia de "desarraigo", de "despoblación de la campaña", de "empobrecimiento [...] de la vivienda y la cocina", de "colapso creador [...] del folklore artístico" (Canal Feijóo 1934, p. 60), en fin, de destrucción del "juego integral de paisaje, costumbres, tonada, locales" (Canal Feijóo 1937, p. 11) que, ya en la década de 1930 y en medio de una tremenda sequía producida por la tala indiscriminada de bosques, el escritor y sociólogo argentino Bernardo Canal Feijóo calificaba de "despaisamiento" de su provincia nativa, Santiago del Estero; neologismo que se proponía entender, además, la "indignada respuesta de [la Naturaleza] a la insensatez con que el hombre la ha venido tratando." (Canal Feijóo 1948, p. 113) Esa "respuesta" comprendería, siempre de acuerdo con Canal, la baja de "los términos medios pluviales", "las erosiones", "la esterilización de la superficie accesible", "la proliferación de las plagas zoológicas" (Canal Feijóo 1948, p. 113) - esto es, lo que hoy llamaríamos irrupción de Gaia o "historia sympoiética" (Haraway 2016: 61) o aceleración de las 
respuestas co-evolutivas por parte de las "naturalezas baratas" a su propia capitalización (Moore 2015: 274). A lo que voy es que, en tanto figura que articula en un mismo plano de enunciación a procesos geoclimáticos y otros de índole culinaria, musical o habitacional, en una situación de crisis acumulativa de un régimen extractivo -el obraje maderero- el término acuñado por Canal Feijóo resulta indudablemente más rico que las versiones posteriores de Jean-François Lyotard o de Jean-Luc Nancy quienes, a finales del siglo veinte, propondrían pensar con el concepto de dépaysement "la implosión de las formas" (Lyotard 1991, p. 189) al interior del género paisaje, el despoblamiento del "país de los paisanos" del que éste -el género o idea del paisaje- sería a la vez agente y síntoma (Nancy 2005: 61).

4 Cuando digo más rico, me refiero a la plasticidad mayor del término de Canal en cuanto a comprender no solo el des-entendimiento entre forma cultural y aquello que ésta contiene apenas en cuanto exceso que la abisma por dentro: ese "país" que, en la jaula del paisaje, no deja de re-presentar su propio ausentamiento, en palabras de Nancy. También incluye, en Canal, su costado productivo, los nuevos ensamblajes de lo viviente o las "naturalezas históricas" (Moore) que se configuran en el in-mundo que surge en ese umbral del fin. Y es más rico, por otra parte porque, a diferencia de las especulaciones del Object-Oriented Ontology acerca de la anterioridad (y por tanto también posteridad) existencial de la materia respecto de lo viviente y la experiencia, las reflexiones del argentino nunca se abstraen de la concretud de un lugar histórico y ecológico cuyo desmoronamiento también pone en suspenso la posibilidad misma de ser pensado. Como sugieren Danowski y Viveiros de Castro, "la idea del fin del mundo necesariamente evoca el problema correlativo del fin del pensamiento, esto es, el fin de la relación (externa o interna) entre pensamiento y mundo" (2017, p. 19). El hecho de que, aquí, esta paradoja emerja como localizada en un tiempo y espacio concreto y cercano, destaca pues al concepto de Canal respecto de sus versiones más recientes. ¿Cómo -se pregunta el santiagueño-nombrar el lugar de la catástrofe si ésta, y las fuerzas exógenas que la impulsan, también ponen en juicio la continuidad misma de ese lugar?

'Despaisamiento' remite en Canal Feijóo a lo que el lenguaje gubernamental actual llamaría una crisis de sustentabilidad: los efectos cumulativos sobre la sociabilidad provinciana -ese 'juego integral' entre cultivos y cultura que habría proveído de espesor, de 'regionalidad' a las provincias del Noroeste argentino- de su inserción en circuitos extractivos de escala mayor como el obraje maderero (la 'industria antiforestal', en la expresión de Canal) y la disputa del suministro acuático por el río Salado con la zafra azucarera y con proyectos hidroeléctricos ubicados en el cauce superior. Lucha a dos frentes, la del bosque y la del agua, que, en la década siguiente, lo llevaría al propio Canal a dar batalla adoptando ahora el lenguaje tecnicista de 'planificación integral'. Esto es, cambia de escala y aboga por la "superación del viejo y ya quizás apenas cartográfico concepto de Provincia, por el más vivo, razonable y realista de Región, en la cual la presuposición meramente cartográfica de la primera, ceda a una idea de anatomización, de integración vertebral, que responda mejor a un ideal de vida plena, orgánica y fecunda" (Canal Feijóo 1948, p. 143). Ya residente él mismo en Buenos Aires, y ante la desesperación que le provocaba el deterioro de su lugar de origen, Canal adopta la mirada anatomopolítica del estadista-ingeniero y desecha sus propias tentativas anteriores de construir lo que, con Latour, podríamos llamar un pensamiento híbrido, pensamiento que aún había querido asumir la "doble interioridad" (Moore 2017) entre regímenes de acumulación y dinámicas medioambientales y de su co-producción activa de repertorios 
culturales y modos de sociabilidad. Ahora, esta dimensión, gracias a la cual dimensiones de poder y de agencialidad local y exógena, humana y ambiental, habían podido concebirse en su "juego" complejo de interrelaciones, es de repente abandonada al abstraerse la mirada a una suerte de gnósis estatal imaginando al Estado como el gran cirujano benigno llamado a intervenir en la trama local precisamente gracias a su supuesta exterioridad respecto a ella.

Repliegue al lenguaje del Estado desarrollista por parte de un intelectual provinciano díscolo que, quiero pensar, aquí como en otras ocasiones en el curso del siglo XX también se produce en reacción a la poca repercusión que generaron esas tentativas de construir lenguajes alternativos de crítica interiorana: entre 1932 y 1934, mientras elabora sus reflexiones en torno al paisaje santiagueño y su destrucción, Canal no consigue atraer una sola colaboración ajena a su revista Ñan ("camino"). Efectivamente, el in-mundo, ese espacio-tiempo de sobrevida que sucede al fin, es también y quizás ante todo una crisis del lenguaje, un momento de enorme dificultad para hacerse entender y para reestablecer comunidad a partir de sentidos compartidos. Cierto, la experiencia de un intelectual de provincias quien, al no encontrar eco a sus ideas, aún puede mudarse a la ciudad-capital y cambiar de conversación, está a años luz de la soledad existencial de una Damiana Kryygi, la niña aché secuestrada y llevada al Museo de La Plata en 1896 cuya vida narra la película de Alejandro Fernández Moujan (2015), o la de Carapiru, protagonista de Serras da Desordem (2006) de Andrea Tonacci, el joven awa-guajá 'rescatado' por la FUNAI brasileña casi cien años después tras haber vagado solitariamente durante una década por el interior nordestino, luego de que las comunidades de ambos fueran masacradas por colonos blancos. Hay una distancia existencial que mide entre las experiencias de despaisamiento de éstos últimos y la de Canal, como también entre la del autor de Confines de occidente y nuestro propio estado de pánico frío -la expresión es de Isabelle Stengersante la amenaza del cambio climático: distancia que tiene que ver, sin duda, con los diferentes grados de exposición a la "zona extractiva" (Gómez-Barris 2017), esa frontera donde el régimen capitalista ha resuelto una y otra vez sus contradicciones internas por la apertura de nuevos repositorios de "naturaleza" disponible para ser apropiada. Esa escala de intensidades incluye también al universo viviente más extenso, donde incrementan a paso acelerado los remanentes huérfanos de procesos co-evolutivos forjados a través de millones de años. ¿Qué pasa -se pregunta Donna Haraway en relación a la ola de extinciones que caracteriza a nuestro presente- "cuando un socio involucrado de manera crítica en la vida de otro desaparece de la tierra? ¿Qué acontece cuando holobiomas enteros se desmoronan hacia los escombros de simbiontes quebrados?" (Haraway 2016, p. 69). La reformulación de la idea de desierto propuesta recientemente por Elizabeth Povinelli como figura "geontológica" sería ciertamente una respuesta sugerente, en tanto nombra "el apartarse de la tierra de ciertas formas de existencia". Un desierto, sugiere Povinelli, no sería por tanto "eso donde no hay vida. El desierto está ahí donde una serie de entidades han retirado su cuidado [care] del tipo de entidades que son los humanos y que, en consecuencia, han transformado a los humanos en otra forma de existencia: hueso, momias, ceniza, suelo" (Povinelli 2016, p. 28).

Pero si la figura del desierto proporcionaría así el horizonte imaginario del cronotopo de nuestra modernidad fósil -aquello que yace en el pasado de lo viviente solo para transformarlo, una vez extraído y combustido, en su imagen y semejanza- la noción del inmundo -aquello que, decía Lyotard, adviene en el despaisamiento- me parece nombrar mejor el trance de soledad existencial que las formas vivas (y las formas de vida humana) 
experimentamos en grados de intensidad vastamente disimilares en la faz de ese horizonte. Dicho de otra manera, el desierto en tanto retirada de cuidados mutuos surge como horizonte aporético en el inmundo, ya que designa la confluencia apenas negativa de singularidades absolutamente insuturables (los 'simbiontes quebrados' de Haraway): muñones de sobre-vida impedidos existencialmente de crear 'mundo'.

Inmundo sería así un nombre para nuestra dificultad -un 'nosotros' dado no como anterioridad sino apenas como potencialidad débil - de trabar nuevas alianzas, de hacer causa común de una condición compartida de sobre-vivientes, como hoy lo están intentando valiosamente nociones como los 'terráneos' de Latour o el llamado compostista de Donna Haraway por inventar novedosas formas de parentesco intra e inter-especie. La diferencia entre inmunidad e inmundo sería, en ese sentido, la que distingue a un pensamiento biopolítico cuyo escudo inmunitario sería la barrera que exigen romper estas nuevas est/éticas de communitas terránea de la soledad de una sobrevida, un resto de simbionte, huérfana de espesor, esto es, desierta de las formas de existencia que eran su "ambiente vital". Es de esta -literalmente- voz en el desierto que dan testimonio, con grados de intensidad vastamente diferente (pero esto es parte del problema) los textos de Canal de los años treinta y los soliloquios de Carapiru en el film de Tonacci, pronunciados ni para la cámara ni tampoco para interlocutores profílmicos sino, quizás, para un destinatario que el re-enactment del film consiga proyectar por momentos, aunque sea como modalidad nemónica. Pero en tanto esa voz en el desierto devuelve una y otra vez a la sobrevida, la singularidad existencial en su concretud, inmundo tal vez también podría ponerse a trabajar como figura crítica: esto es, como lo que resiste, lo que hace tropezar, al giro universalizante que se cuela aún en los diagnósticos de crisis planetaria como el del antropoceno, con su -literalmente- deus ex machina del hombreespecie como agente geológico y sujeto histórico a la vez (Chakrabarty 2015). Frente al antropoceno y de su retórica neo-malthusiana "de integración vertebral" entre bio- y geopolítica, quisiera proponer, que el inmundo y sus voces en el desierto nos devuelven hoy a las zonas de exclusión/extracción donde ya tiene, incesantemente y de mil maneras, el evento del fin del mundo (pero no del "Mundo") y donde, por ende, también se están forjando técnicas y lenguajes de sobre-vida. Las nuevas "artes de la zona extractiva" -parafraseando a Mary Louise Pratt (2018) y a Macarena Gómez-Barris (2017)consisten en ensamblajes radicalmente locales, esto es, su condición de sobre-vida (de formar comunidad en el desierto) sería tal vez precisamente esa resistencia a la generalización, a la langue y al concepto. Inmundo: humillación de la teoría, obligándonos a dejar el mirador del fin del mundo -a dejar de mirar hacia el horizonte del desierto como si ahí hubiera aún un paisaje- y a inmiscuirnos en esa singular y paradójica sobrevida "porque -como dice el poeta pernambucano João Cabral de Melo Neto (2008, p. 92)- "é muito mais espessa / a vida que se desdobra / em mais vida". 


\section{BIBLIOGRAPHY}

Andermann, J. (2018). Tierras en trance. Arte y naturaleza después del paisaje. Santiago de Chile: Ediciones Metales Pesados.

Baichwal, J. (2006). Manufactured Landscapes (película). Canada 2006, 90 min.

Canal Feijóo, B. (1934). El asalto a la selva. En Ñan - Revista de Santiago 2: 60-76.

-----. (1937). Ensayo sobre la expresión popular artística en Santiago. Buenos Aires: Compañía Impresora Argentina.

-----. (1948). De la estructura mediterránea argentina. Buenos Aires: Ed. López.

Chakrabarty, D. (2015). The Human Condition in the Antropocene. Tanner Lectures in Human Values. Yale University. [On Line]. Disponible en: https://tannerlectures.utah.edu/Chakrabarty\% 20manuscript.pdf

Danowski, D. y Viveiros de Castro, E. (2017). The Ends of the World. Cambridge: Polity Press. (orig. Há Mundo Por Vir? Ensaio Sobre os Medos e os Fins. Florianópolis: Desterro).

Fernández Mouján, A. (2015). Damiana Kryygi (película). Argentina 2015, 94 minutos.

Gómez-Barris, M. (2017). The Extractive Zone. Social Ecologies and Decolonial Perspectives. Durham, NC: Duke University Press.

Haraway, D. J. (2016). Staying With the Trouble. Making Kin in the Chthulucene. Durham, NC: Duke University Press.

Latour, B. (2017). Facing Gaia. Eight Lectures on the New Climatic Regime. Cambridge: Polity Press.

Lyotard, J. (1991). 'Scapeland,' en: The Inhuman. Reflections on Time. Cambridge, Polity Press: 182-190.

Moore, J. W. (2015). Capitalism in the Web of Life. Ecology and the Accumulation of Capital. London: Verso.

Morton, T. (2013). Hyperobjects. Philosophy and Ecology After the End of the World. Minneapolis: University of Minnesota Press.

Nancy, J. (2005). 'Uncanny Landscape,' en The Ground of the Image. New York, Fordham University Press: 51-62.

Neto, João Cabral de Melo. (2008). Poesia completa e prosa. Rio de Janeiro: Nova Aguilar.

Povinelli, E. (2016). Geontologies. A Requiem to Late Liberalism. Durham, NC: Duke University Press.

Pratt, M. L. (2018). Los Imaginarios Planetarios. Madrid: Aluvión.

Stengers, I. (2015). In Catastrophic Times. Resisting the Coming Barbarism. Ann Arbor: Open Humanities Press.

Tonacci, A. (2006). Serras da Desordem (película). Brasil 2006, 135 minutos. 


\section{AUTHOR}

JENS ANDERMANN

New York University - ja138@nyu.edu 